\title{
Trauma Surgery $\&$ Acute Care Open \\ Damage control hip disarticulation: two-stage operation with index creation of a large medial flap for the septic hip
}

\author{
Christina Colosimo ำ , ${ }^{1}$ Charles Fredericks, ${ }^{2}$ James R Yon, ${ }^{3}$ John C Kubasiak, ${ }^{2}$ \\ Faran Bokhari, ${ }^{4}$ Stathis Poulakidas ${ }^{4}$
}

'Department of Trauma, Sky Ridge Medical Center, Lone Tree, Colorado, USA

2Department of General Surgery, Rush University Medical Center, Chicago, Illinois, USA

${ }^{3}$ Department of Trauma and Acute Care Surgery, Swedish Medical Center, Englewood, Colorado, USA

${ }^{4}$ Department of Trauma And Burn, John H Stroger Hospital of Cook County, Chicago, Illinois, USA

Correspondence to Dr Christina Colosimo; chris. colosimo@gmail.com

Received 28 May 2020 Revised 11 July 2020 Accepted 5 August 2020 (c) Author(s) (or their employer(s)) 2020. Re-use permitted under CC BY-NC. No commercial re-use. See rights and permissions. Published by BMJ.

To cite: Colosimo C Fredericks C, Yon JR, et al. Trauma Surg Acute Care Open 2020:5:e000502.

\section{ABSTRACT \\ Background Although rarely performed, hip} disarticulation (HD) is usually used for the patient with a non-viable leg who is also in extremis. HD was first used for trauma and infection; however, the technique was perfected during the age of hindquarter amputation for osteosarcomas. The operation performed by most surgeons today is still based on the oncological principles of high vessel control and ligation. When this approach has been used in the overwhelmingly infected or mangled extremity, it has resulted in high mortality rates. During the last 20 years, the concept of damage control operation has been embraced by emergency surgeons in all fields. We sought to extrapolate this concept and to apply it to the non-viable lower extremity.

Methods We describe a new concept of damage control HD, review the technique and discuss our consecutive series of nine patients who underwent the procedure for trauma or necrotizing infection without flap dehiscence or mortality.

Results All patients survived to hospital discharge. At time of discharge or at follow-up, six of the nine patients were able to transfer to a wheelchair.

Discussion Proper disarticulations for infection need to address these two operative and postoperative issues: damage control debridement with creation of sufficient flap size and thorough postoperative wound care. Level IV

\section{INTRODUCTION}

Hip disarticulation (HD) is rarely used. It is a lastresort strategy in severe trauma or necrotizing infections of the lower extremity and accounts for $0.5 \%$ of amputations yearly. ${ }^{1}$ Although this operation can be a life-saving operation, it is associated with a mortality as high as $33 \%$ to $44 \%$, and wound complication rates approach $83 \% .{ }^{23}$ Severe sepsis and the resultant large-volume resuscitation and heavy infectious burden lead to an edematous stump at risk of dehiscence, flap necrosis and reinfection. Therefore, HD must balance expedient and complete debridement with preparation of optimal soft tissue coverage. Often, patients present with hemodynamic instability and other physiological markers of shock as a result of their infectious burden and underlying comorbidities. We extrapolated the 'damage control operation' concept from trauma and emergency general operation and applied it to the HD population. ${ }^{4}$ Goals remain the same as for the exsanguinating trauma patient: rapid debridement of devitalized tissue, source control, temporary closure and a return to the critical care unit for ongoing resuscitation. Only when the patient has stabilized are definitive reconstruction of the stump site and closure attempted. The aim of this study was to describe a series of nine patients who underwent damage control hip disarticulation (DCHD) for infection or trauma in a staged approach using negative pressure wound therapy (NPWT) between operations.

\section{PATIENTS AND METHODS}

After institutional review board approval, we conducted a retrospective review of a consecutive series of nine patients who underwent two-stage HD from 2008 to 2014. All patients had a unilateral procedure; no patients underwent bilateral HD. Emergency and urgent amputations were performed for eight patients who presented with necrotizing soft tissue infections (NSTIs) and sepsis. In this group, the operation was performed within 24 hours from admission. All of the patients who had NSTI had multiple comorbidities. Most patients had paraplegia secondary to gunshot wound and resultant ischial or sacral ulcers as an underlying diagnosis. A single patient underwent HD due to mangled extremity secondary to trauma.

\section{Description of procedure}

The method described by Sugarbaker et al is a commonly used approach for HD. ${ }^{56}$ It is an evolution of the methods used for an oncological resection for sarcoma or osteosarcoma. Thus, the primary focus is initial high ligation of the femora vessels, then resection of the femoral head and removal of muscular tissue, culminating in a gluteal flap to cover the surgical site. ${ }^{6}$ We sought to direct the primary focus on the operation on both excision of any marginal or infected tissue, and preservation of viable tissues for adequate coverage. To achieve these goals, we focused on the area of infection first.

At the beginning of the operation, the patient is positioned in the lateral decubitus position with the affected side up. An incision was made along the entire length of the anterolateral surface of the outer thigh, with incorporation of the wound into the central incision. Superior dissection is performed up to the level of the hip joint capsule, where the femoral head is dissected free (figure 1). Dissection is carried inferiorly down to the femur through the tensor fascia lata. The musculature was mobilized 


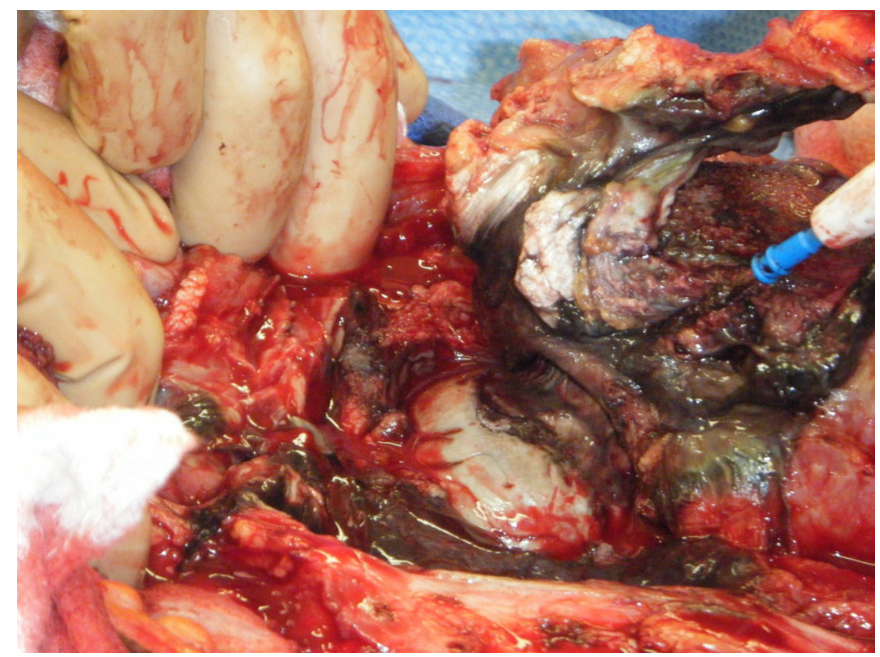

Figure 1 Femoral head is dissected free.

off of the femur using a periosteal elevator. After control of the popliteal vessels, a large medial myocutaneous flap was created (figure 2). Exact muscles included, as well as the shape of the flap, are dependent on what tissue is viable, but we typically include the hip adductors. The femoral artery, nerve and vein are not dissected and are avoided. Preservation of the neurovascular bundle allows for a large perfused flap. An NPWT device is placed for temporary wound coverage. After the index operation, all patients were admitted to the burn or trauma intensive care units for ongoing critical care support. NPWT is used for 2 to 3 weeks until output is $<100 \mathrm{cc} /$ day and the flap is no longer

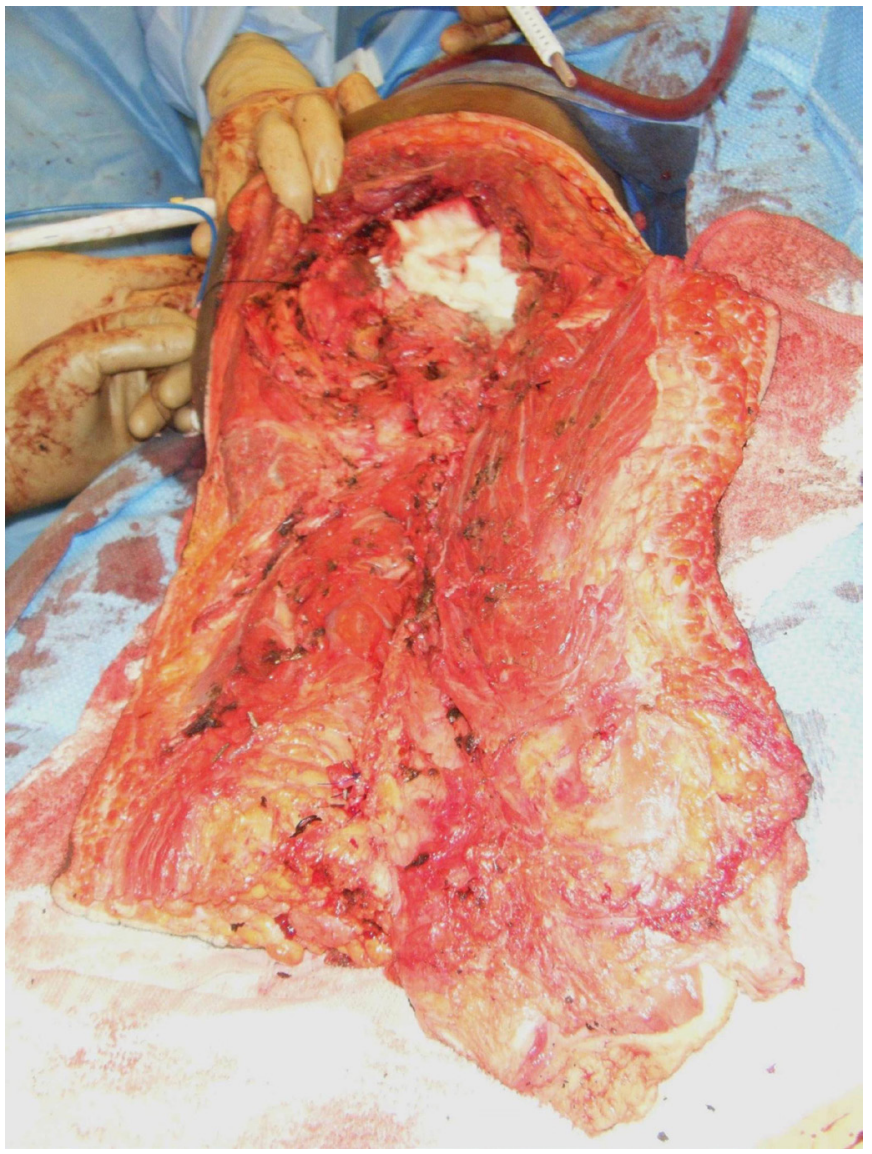

Figure 2 A large medial myocutaneous flap is created.

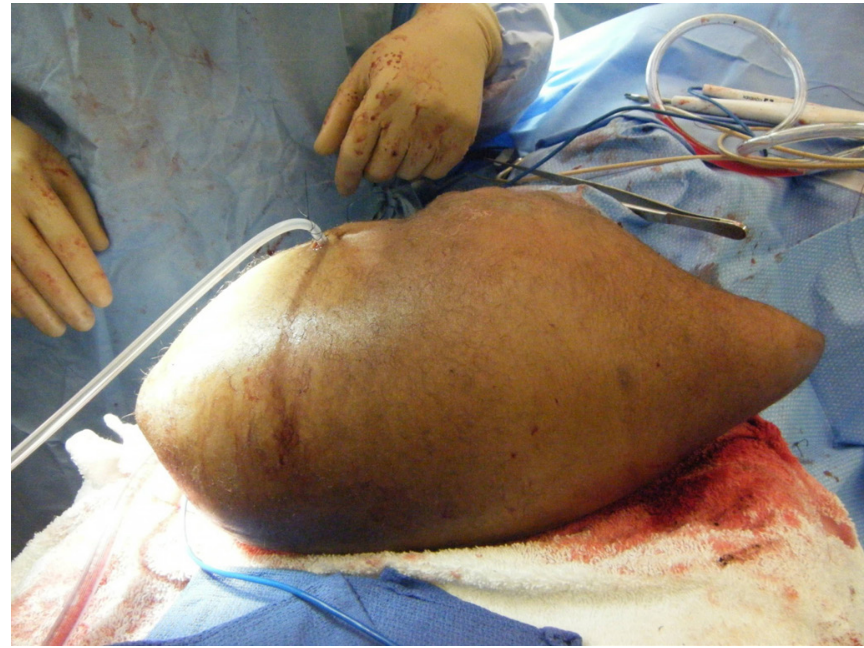

Figure 3 The flap is closed to cover the defect, with drains to prevent a seroma.

edematous. The flap is then folded on itself to cover the defect, with drains to prevent seroma (figure 3).

\section{RESULTS}

There were seven male patients and two female patients with an average age of 40 years (SD 12.8) (table 1). Of the total number of patients, $66.67 \%$ were paraplegic with decubitus ulcers.

The patients underwent an average of 2.78 (SD 1.09) operations (table 2). The average hospital length of stay was 54.22 (SD 63.94) days after index operation. Although there were some complications, most notably acute respiratory distress syndrome, there were no episodes of flap dehiscence or deep infection. All patients survived to hospital discharge. At the time of discharge or at follow-up, six of the nine patients were able to transfer to a wheelchair.

\section{DISCUSSION}

First described in 1774, the indications for performing disarticulation of the hip have come full circle. ${ }^{7}$ Rarely used in the civilian sector with high mortality during the 18th and 19th centuries, it was used most often by the military during this period to manage catastrophic injury or secondary infection.? Over the course of the 20th century, HD became widely used for oncological resections, as the consensus of the time was that the entire femur needed to be removed for cancer-free outcome. ${ }^{8}$ As limb-sparing operation has become the gold standard, HD is once again being used primarily in the setting of severe trauma or infection. ${ }^{6}$ Regardless of source, operative management of the infected hip requires timely and complete debridement of necrotic tissue to stem the tide of sepsis. Common infectious sources include decubitus ulcers, orthopedic prosthesis, underlying osteomyelitis, ischemic limbs, failed revascularization or previous amputation sites. ${ }^{1}$ Debridement and disarticulation for proper source control should follow expeditiously; emergency operations carry an increased risk of mortality. ${ }^{2}$ A recent case study found mortality was higher in disarticulations with trauma $(66.7 \%)$ versus tumorous $(60 \%)$ diagnoses. ${ }^{9}$

Similarly, the risk of postoperative infection, flap necrosis and wound dehiscence increases with emergency operation. Other known risk factors include peripheral vascular disease and previous above-knee amputation. ${ }^{2}$ The most significant 


\begin{tabular}{lllllll}
\hline Table 1 & Demographic information & & & & \\
\hline Patient & Age range (years & Sex & Diagnosis & Operative indication & Comorbid conditions & Urinary tract infection \\
\hline 1 & $55-60$ & F & Vulvar cancer & NSTI & Stroke, DM & Yes \\
2 & $40-45$ & F & Sacral ulcer & NSTI & HTN, DM, recent cardiac arrest & No \\
3 & $25-30$ & M & Trauma & Trauma & None & No \\
4 & $55-60$ & M & Ischial ulcer & NSTI & GSW, paraplegia & No \\
5 & $30-35$ & M & Sacral ulcer & NSTI & GSW, paraplegia & Yes \\
6 & $40-45$ & M & Sacral ulcer & NSTI & GSW, paraplegia, UTI & Yes \\
7 & $20-25$ & M & Sacral ulcer & NSTI & GSW, paraplegia & Yes \\
8 & $30-35$ & M & Ischial ulcer & NSTI & GSW, paraplegia & No \\
9 & $50-55$ & M & Sacral ulcer & NSTI & GSW, paraplegia & No \\
\hline
\end{tabular}

DM, diabetes mellitus; F, female; GSW, gunshot wound; HTN, hypertension; M, male; NSTI, necrotizing soft tissue infection; UTI, urinary tract infection.

complication is flap loss, which requires complex reconstruction for coverage.

Therefore, proper disarticulations for infection need to address these two operative and postoperative issues: damage control debridement with creation of sufficient flap size and thorough postoperative wound care. Proper source control is a fundamental tenet of the Surviving Sepsis Campaign..$^{10}$ A damage control approach is a validated method of timely source control in the abdomen, as well as the extremities. ${ }^{411} 12$ It allows for an abbreviated operative time and continued postoperative resuscitation. Hypotension, inadequate arterial inflow, and edema after large-volume resuscitation may result in delayed demarcation of ischemia, and flap viability should be assessed over time prior before definitive closure.

Our creation of a large medial flap allowed for adequate soft tissue coverage with easy dissection. Previous studies found no significant difference in postoperative wound complications between wounds closed primarily or left open after HD. ${ }^{2}$ Wound complications can arise more frequently in patients experiencing hypothermia, which is another factor in favor of DCHD. ${ }^{13}$ In addition to providing coverage, another positive mechanism behind our choice of NPWT is the increase in blood flow and granulation tissue and elimination of edema and exudate. ${ }^{14} 15$

Our series had an average hospital stay of 54.22 days, and excluding the patient who also had cancer and an extended stay resulted in an average stay of only 33.5 days for the rest of the patients. This is comparable to the series by Zalavras et al of 42 days. ${ }^{1}$ Functional recovery after HD is a difficult scenario to manage as loss of hip means loss of fulcrum, which makes basic wheelchair transfer difficult. However, the majority of our patients were able to eventually self-transfer to a wheelchair,

Table 2 Operative and postoperative information

\begin{tabular}{llllll}
\hline Patient & $\begin{array}{l}\text { LOS } \\
\text { (days) }\end{array}$ & OR visits & $\begin{array}{l}\text { Ventilator } \\
\text { days }\end{array}$ & $\begin{array}{l}\text { Acute } \\
\text { respiratory } \\
\text { distress } \\
\text { syndrome }\end{array}$ & $\begin{array}{l}\text { Self-transfer to } \\
\text { wheelchair }\end{array}$ \\
\hline 1 & 220 & 5 & 17 & Yes & No \\
2 & 55 & 4 & 50 & No & No \\
\hline 3 & 15 & 2 & 0 & No & Yes \\
\hline 4 & 24 & 2 & 0 & No & Yes \\
5 & 32 & 2 & 26 & Yes & Yes \\
6 & 17 & 3 & 0 & No & No \\
7 & 48 & 3 & 2 & No & Yes \\
8 & 52 & 2 & 0 & No & Yes \\
9 & 25 & 2 & 0 & No & Yes \\
\hline
\end{tabular}

LOS, length of stay; OR, operating room. which we attribute to a larger flap that still allows some support for sitting for the patient.

A multidisciplinary approach with surgical, wound care and rehabilitation services is paramount for best management. At our institution, the burn service is often consulted for management of sacral decubitus ulcers. Proper wound care must attempt to address the infectious source; a recent article demonstrated a $63 \%$ reinfection rate of decubitus ulcers in spinal cord injured patients. ${ }^{16}$ Postoperatively, the patients receive care in the intensive care unit with experienced nurses to perform dressing changes. The loss of fulcrum at the hip increases energy expenditure after $\mathrm{HD}$ with intense need for physical therapy. ${ }^{1{ }^{7}}$ The major limitation of our article is the small sample size; however, due to the low incidence of severe trauma or devastating infection, it is difficult to accrue large numbers of this patient population in a single center. DCHD is a new two-stage technique which may offer improved morbidity and decreased mortality; however, further prospective observation of this approach is needed.

The damage control approach to HD for the septic joint affords improved outcomes compared with traditional methods. The two stages afford both removal of the septic focus and time for stabilization of the patient and resolution of edema in the myocutaneous flap. NPWT, by reducing the bacterial load and edema, may have contributed to the improved morbidity. DCHD is a useful tool in the surgeon's armamentarium when faced with the overwhelmingly infected hip joint or non-viable extremity.

Contributors $\mathrm{CC}$ helped with the literature search and writing of the article. CF helped with the data collection and literature search. JY helped write the article. JCK helped with the project design, data analysis and editing. FB and SP both helped with project design and editing.

Funding The authors have not declared a specific grant for this research from any funding agency in the public, commercial or not-for-profit sectors.

Disclaimer The views expressed in the submitted article are her own and not an official position of the institution.

Competing interests None declared.

Patient consent for publication Not required.

Provenance and peer review Not commissioned; externally peer reviewed.

Data availability statement All data relevant to the study are included in the article or uploaded as supplementary information. All data relevant to the study are included in the article or uploaded as supplementary information.

Open access This is an open access article distributed in accordance with the Creative Commons Attribution Non Commercial (CC BY-NC 4.0) license, which permits others to distribute, remix, adapt, build upon this work non-commercially, and license their derivative works on different terms, provided the original work is properly cited, appropriate credit is given, any changes made indicated, and the use is non-commercial. See: http://creativecommons.org/licenses/by-nc/4.0/.

ORCID iD

Christina Colosimo http://orcid.org/0000-0002-4722-2984 


\section{REFERENCES}

1. Zalavras CG, Rigopoulos N, Ahlmann E, Patzakis MJ. Hip disarticulation for severe lower extremity infections. Clin Orthop Relat Res 2009;467:1721-6.

2. Endean ED, Schwarcz TH, Barker DE, Munfakh NA, Wilson-Neely R, Hyde GL. Hip disarticulation: factors affecting outcome. J Vasc Surg 1991;14:398-404.

3. Unruh T, Fisher DF, Unruh TA, Gottschalk F, Fry RE, Clagett GP, Fry WJ. Hip disarticulation. An 11-year experience. Arch Surg 1990;125::791-793.

4. Sagraves SG, Toschlog EA, Rotondo MF. Damage control surgery--the intensivist's role J Intensive Care Med 2006;21:5-16.

5. Sugarbaker PH, Chretien PB. A surgical technique for hip disarticulation. Surgery 1981;90:546-53.

6. Sugarbaker P, Malawer M, Disarticulation H. Disarticulation. In: Malawer M, Wittig JC, Bickels J, Operative techniques in orthopaedic surgical oncology. Philadelphia, PA: Lippincott Williams \& Wilkins, 2001:337-58.

7. Wakelin SJ, Oliver CW, Kaufman MH. Hip disarticulation--the evolution of a surgical technique. Injury 2004;35:299-308.

8. Jain R, Grimer RJ, Carter SR, Tillman RM, Abudu AA. Outcome after disarticulation of the hip for sarcomas. Eur J Surg Oncol 2005;31:1025-8.

9. Moura DL, Garruço A. Hip disarticulation - case series analysis and literature review. Rev Bras Ortop 2017;52:154-8.
10. Dellinger RP, Levy MM, Carlet JM, Bion J, Parker MM, Jaeschke R, Reinhart K, Angus DC, Brun-Buisson C, Beale R, et al. Surviving sepsis campaign: international guidelines for management of severe sepsis and septic shock: 2008. Intensive Care Med 2008;34:17-60.

11. Stone HH, Strom PR, Mullins RJ. Management of the major coagulopathy with onset during laparotomy. Ann Surg 1983;197:532-5.

12. Weber DG, Bendinelli C, Balogh ZJ. Damage control surgery for abdominal emergencies. Br J Surg 2014;101:e109-18.

13. Stone PA, Flaherty SK, Aburahma AF, Hass SM, Jackson JM, Hayes JD, Hofeldt MJ, Hager CS, Elmore MS. Factors affecting perioperative mortality and woundrelated complications following major lower extremity amputations. Ann Vasc Surg 2006;20:209-16.

14. Hunter JE, Teot L, Horch R, Banwell PE. Evidence-based medicine: vacuum-assisted closure in wound care management. Int Wound J 2007;4:256-69.

15. Vikatmaa $P$, Juutilainen $V$, Kuukasjärvi $P$, Malmivaara $A$. Negative pressure wound therapy: a systematic review on effectiveness and safety. Eur J Vasc Endovasc Surg 2008;36:438-48.

16. Jugun K, Richard J-C, Lipsky BA, Kressmann B, Pittet-Cuenod B, Suvà D, Modarressi A, Uçkay I. Factors associated with treatment failure of infected pressure sores. Ann Surg 2016;264:399-403.

17. Nowroozi F, Salvanelli ML, Gerber LH. Energy expenditure in hip disarticulation and hemipelvectomy amputees. Arch Phys Med Rehabil 1983;64:300-3. 